\title{
Working from home during the COVID-19 pandemic: Impact on office worker productivity and work experience
}

\author{
Mohamad Awada ${ }^{\mathrm{a}}$, Gale Lucas ${ }^{\mathrm{b}}$, Burcin Becerik-Gerber ${ }^{\mathrm{a}, *}$ and Shawn Roll ${ }^{\mathrm{c}}$ \\ ${ }^{a}$ Department of Civil and Environmental Engineering, University of Southern California, Los Angeles, CA, USA \\ ${ }^{\mathrm{b}}$ USC Institute for Creative Technologies, University of Southern California, Los Angeles, CA, USA \\ ${ }^{\mathrm{c} C h a n ~ D i v i s i o n}$ of Occupational Science and Occupational Therapy, University of Southern California, Los \\ Angeles, CA, USA
}

Received 24 February 2021

Accepted 5 May 2021

\begin{abstract}
.
BACKGROUND: With the COVID-19 pandemic, organizations embraced Work From Home (WFH). An important component of transitioning to WFH is the effect on workers, particularly related to their productivity and work experience.

OBJECTIVES: The objective of this study is to examine how worker-, workspace-, and work-related factors affected productivity and time spent at a workstation on a typical WFH day during the pandemic.

METHODS: An online questionnaire was designed and administered to collect the necessary information. Data from 988 respondents were included in the analyses.

RESULTS: Overall perception of productivity level among workers did not change relative to their in-office productivity before the pandemic. Female, older, and high-income workers were likely to report increased productivity. Productivity was positively influenced by better mental and physical health statuses, having a teenager, increased communication with coworkers and having a dedicated room for work. Number of hours spent at a workstation increased by approximately 1.5 hours during a typical WFH day. Longer hours were reported by individuals who had school age children, owned an office desk or an adjustable chair, and had adjusted their work hours.

CONCLUSION: The findings highlight key factors for employers and employees to consider for improving the WFH experience.
\end{abstract}

Keywords: Remote work, workspace, work hours, workstation, office work, socioeconomic impact

\section{Introduction}

The novel SARS-CoV-2 virus (COVID-19) is transforming life as we know it; every aspect of our lives has been affected by the outbreak and this effect is expected to endure. The organization and completion of work have been impacted across nearly

\footnotetext{
*Address for correspondence: Burcin Becerik-Gerber, Department of Civil and Environmental Engineering, University of Southern California, Los Angeles, CA, USA. E-mail: becerik@ usc.edu.
}

all industry sectors, including educational and information services, governments, healthcare and social services and many other professional and business services, raising concerns about the resilience of various parts of our lives to any new rare and extreme event [1]. To enhance their corporate resilience and safeguard the community's health and well-being, organizations that have been hit significantly by the pandemic rapidly embraced the concept of remote working, also known as work from home (WFH) [2, 3]. Shifts to WFH due to the pandemic have sparked 
discussions about the future of office work that can adopt innovative methods, support new practices, and embrace the idea of a virtual workforce [4]. Anticipation of a future where workers are all detached from the office space dates back to the 1980s [5]; yet, it was not until nearly 40 years later that WFH became a widespread necessity to mitigate the spread of a pandemic.

An important component of transitioning to WFH is the effect on the work and the workers [6], particularly related to performance, health, and well-being. Under ideal circumstances, several prior studies concluded that WFH is associated with at least similar productivity levels compared to typical office work [7] and supports are often made available to help workers who chose WFH. The pandemic induced WFH allows for a unique exploration of a wide variety of work, workplace, and worker factors that have not been previously examined under ideal circumstances. For example, the abrupt shift for working parents whose children are in remote school or workers with other care giving responsibilities [8] oblige those workers to change their usual work hours or schedule their working hours around others more than individuals who live alone or do not have children [9]. Similarly, differences in the home workspace, such as uncontrollable noise, loss of privacy, and comfort and proxemics [10] can all affect workers' engagement, performance, health and well-being [11, 12], especially when organizational practices and policies are not in place to support the WFH transition.

Given the incremental advances in understanding the effects of WFH, there are significant gaps in our understanding of the most salient factors impacting workers' performance as it relates to their health and well-being. As WFH became a necessity for a vast majority of white-collar workers during the COVID19 pandemic, an opportunity emerged to examine the effects across a wide variety of worker, workspace, and work factors that may not be as easily examined under more ideal or limited scale/scope of WFH situations. Therefore, we conducted an online survey study to investigate and examine the transition to WFH during the pandemic period for office workers, specifically two components of work performance: productivity and work engagement.

This work contributes to the state-of-the-art research in the following ways: First, this study informs the literature regarding the influence of a sudden shift to WFH on work experience during the pandemic. Specifically, we examined the effects of this transition on workers' productivity and the dura- tion of time they spend working at their workstations. Second, to provide a picture of how this experience varies among workers, we also examined the productivity and time spent at the workstation based on the workers' demographics, workspace characteristics, and work context. The following three pillars were used based on the definition of future of work which encompasses three deeply connected parameters: the work (the what), the workspace (the where) and the worker (the who) [13]. Third, and beyond research implications, the conclusions and results acquired from this study have direct practical applications that can be applied by workers and employers to improve the WFH experience through workplace practices and policies, all of which can support positive work performance and worker well-being.

\section{Literature review}

Following the COVID-19 pandemic, companies and organizations now aim to engage the work, workforce, and workplace in a new system that identifies the work as a set of tasks to be completed, rather than linking it with a specific location. The WFH situation is likely to become part of future office work and as such, it is important to understand the effects of the three aspects of future work -the worker, workspace and work [5, 13] - relative to the WFH experience.

\subsection{Worker characteristics}

The WFH experience is inevitably influenced by worker demographics, including gender, age, and income [14]. Even in 2021, gender gaps in the workplace and at home persist [15], which might lead to the assumption that women have lower productivity than men because women spend more time on household chores and child caregiving [16, 17]. However, research prior to the pandemic has shown that women's productivity is similar -if not highercompared to men's productivity [18]. Income and age have also been well-studied relative to work-related productivity, noting that higher-waged, middle-aged workers are more productive than lower-waged, younger counterparts $[19,20]$.

The impact of these demographic factors on productivity in remote work is less clear. Applying a traditional perspective of women's engagement in household tasks would suggest potential negative impacts on productivity, while an equity approach that considers increased involvement of men in 
household duties could level any gender gaps in effects on productivity during remote work [17]. Similarly, other factors at home, such as the presence of family members due to the pandemic, could alter the conventional age-income-productivity association. For example, middle-aged workers who are working alongside their children, could become overwhelmed due to parenting demands at the expense of their work engagement and this can negatively impact their productivity [21].

In addition to the demographic factors, WFH may create different challenges for workers with different occupational backgrounds. Prior studies have investigated the impact of WFH on productivity within specific groups of workers (e.g., workers of a Chinese travel agency [7], workers of U.S. Patent and Trademark Office [22]). However, there has not been a study that investigated effects of WFH on productivity across different occupational groups. A transition to remote work would likely have low risk of loss in efficiency for workers who primarily engage directly with computer workstations throughout their day (e.g., programmers) as opposed to individuals working in jobs that require mixed tasks in an interpersonal environment (e.g., health care office workers). In addition to potential negative impact on efficiency in job performance, some of these occupational groups that do not typically spend their entire day at a computer would likely experience a dramatic shift in the amount of sedentary time at their workstations. For example, WFH during the pandemic has led lawyers and judges to spend more time at their workstations to virtually attend court trials [23].

Increased sedentary work and other potential aspects of personal health and well-being are important considerations in the discussion of WFH. Importantly, worker health has been consistently associated with productivity, such that the more health issues workers report the worst their productivity levels are [24]. A variety of physical health issues such as eye strain, nose related symptoms, fatigue, and headache, as well as mental health issues such as anxiety, depression, stress, and insomnia can all have a negative impact on productivity. Specifically, there is a growing body of evidence related to the concept of worker presenteeism that demonstrates degraded work performance due to the existence of physical and mental health issues [25]. Although it may be more easily concluded that these relationships would exist similarly in remote contexts, there are limited studies that examine the impact of worker health on productivity while WFH. Based on this review, we pose the following research question:

Research question 1: Do workers' demographics (i.e., gender, age, income, and occupation) and their physical and mental health statuses affect workers' productivity and the time spent at workstation when work is performed from home during the pandemic period?

\subsection{Workspace context}

Workspace context plays a major role in shaping the work experience. Satisfaction with one's workspace, privacy, and ability to personalize workspace are predictors for workers productivity $[26,27]$. The shift from working in a well-established office space to work from home can be challenging for many office workers. Such challenges can be stressful and might negatively affect a worker's desire to work and thus reduce their productivity. Having the optimal physical setup, proper ergonomics and the necessary equipment is crucial to create an effective workspace that boosts productivity and increases the workers' engagement with their workstation. In their analysis of the workforce shift to the WFH, Moretti et al. [28] explained that workers are expected to engage extensively with their workstations while working from home, and therefore presented their suggestions for a comfortable workstation (i.e., an adjustable desk and chair to prevent back and joints pain, along with a footrest, and an adjustable monitor screen).

Research also shows that separating the workspaces from living spaces is an important factor when working remotely. It is recommended to have a dedicated workspace to create physical boundaries, help workers establish a productive work atmosphere, increase workers desire to stay longer hours at their workstation and signal to other household members that they do not want to be distracted [29]. Yet, when the space at home is limited and several members of the household need a space to work, sharing the same workspace might become inevitable. In fact, in a survey conducted by Suart et al. [30], it was found that only $48.6 \%$ of the respondents had a dedicated workspace, $31 \%$ were sharing their workspace with others and the remaining $20.4 \%$ were working in a variety of places in their homes. However, research shows that productivity decreases with lack of ability to adjust/personalize workspace as well as lack of storage space [31]. On the other hand, Rudnicka et al. [32] conducted a survey about the WFH during 
the COVID-19 era and found that some respondents felt that constantly changing the workspace helped them focus and enhanced their work performance.

In addition to the workspace, indoor environmental quality (IEQ) (e.g., lighting, temperature, ventilation, air quality, noise) also plays a major role in creating a comfortable work experience [33]. Research studies that investigated the effect of IEQ parameters on worker performance suggest that the more satisfied the workers are with the IEQ, the more productive they are $[34,35]$, an effect that is stronger in private offices as opposed to shared offices [36]. In fact, increasing daylight illumination in office spaces can increase workers' performance by $13 \%$ while also reducing fatigue [37]. Beyond lighting, improvement in indoor air quality and thermal conditions have also been linked to enhanced productivity, as well as increased attention and concentration [38]. Research supports that the more control individuals have over their environments, the more satisfied they are with it [39], thus having access to environmental controls might also improve worker productivity. While one might expect to find a similar relation between IEQ satisfaction and productivity during WFH, it is important to investigate this relation for home offices. Following this review, we investigated the effect of the workspace characteristics on the WFH experience during the pandemic.

Research question 2: Do workspace characteristics (having a dedicated space, sharing the workspace with others, availability of office furniture/equipment, and satisfaction with the indoor environmental quality factors) affect workers' productivity and the time spent at workstation when work is performed from home during the pandemic period?

\subsection{Work context}

Another important consideration in worker productivity and work experience when WFH is the ability of workers to set and maintain appropriate boundaries between work duties and house responsibilities. With role conflicts, workers used to find it challenging to manage work and family/life commitments, even before the pandemic era [40, 41]. With workers shifting to WFH abruptly with the pandemic, new forms of conflicts between work and life occurred. When working and living in the same space, setting boundaries between the work and life becomes more challenging. For example, the sense of time might fade in the homogeneous work-home environment and workers might elongate their working hours, start working earlier, later or on the weekends [42]. Some workers might embrace the flexibility in their work hours while other workers might have no choice but to schedule their working hours around their household members or responsibilities [43].

At the same time, the unclear boundaries between home and office might have increased work expectations [44]. For example, Peasley et al. [45] found that sales personnel felt burned out when trying to meet the management's expectations and they believed that job expectations became higher as soon as they started working from home during the COVID-19 pandemic. With this increase in expectations, workers might be tasked with more duties and expected to deliver additional work, increasing working hours and requiring them to spend additional time at their workstations [46]. Meanwhile, communication among different parties (e.g., coworkers, supervisors, employers), which is crucial to keep the remote workers productive, might be impaired as communication during the pandemic usually comes in one form: virtual and is limited by personal, organizational and technological means. Yet, communication provides work resilience by sustaining the usual work operations and is key to mitigating the undesired effects of the sudden shift to WFH [47]. Thus, the impact of work adjustments and work expectations on workers' productivity and work engagement needs to be further investigated, which leads to the following research question:

Research question 3: Do work conditions (adjustment to work schedules, communication with coworkers, workload expectations distractions while working, having other family members at home, the support or lack of from employer) affect workers' productivity and the time spent at workstation when work is performed from home during the pandemic period?

The following sections of the paper are organized as follows: The methods section explains in detail the data collection procedure and describes the control, dependent and independent variables selected based on the framework adopted in this study. The results section provides a summary of the statistical analysis conducted with focus on relative impact of variables within each of the three pillars. Finally, the discussion section offers a detailed interpretation of the study findings and identifies key considerations for implementing WFH as an organizational strategy in future work. 


\section{Methods}

Built on the background literature that examines the relationships of the three pillars of future work, this study aimed to understand how a wide range of worker, workspace, and work context factors affected productivity and time spent at a workstation on a typical WFH day during the pandemic. This section explains in detail the data collection procedure and describes the control, dependent and independent variables selected based on the framework adopted in this study.

\subsection{Respondents}

An online questionnaire was designed and administered through Qualtrics Panel Services for 45-days from April 27, 2020 to June 11, 2020. The study was reviewed by the Institutional Review Board of the University of Southern California and was approved as exempt research (UP-20-00339 IRB study number). Following initial email and public posts to social media pages, 1,409 respondents completed the survey voluntarily without any compensation. Of the 1,409 responses, 91 responses were screened out because the individuals were not working from home at a workstation during the COVID-19 pandemic. Furthermore, 330 responses were excluded because the respondents completed less than a quarter of the survey. Our final sample consisted of the remaining 988 respondents (558 women, 317 men, 113 unreported) who ranged from 18 years old to 80 years old $(M=40.9$ years, $\mathrm{SD}=13.1$ years $)$. Respondents were primarily Caucasian (60.9\%), followed by Asian (24.6\%), Hispanic or Latinx $(9.3 \%)$, Black $(2.8 \%)$, and another race or ethnicity $(2.4 \%)$. Responses were received from 40 states, with the most respondents from California (47.3\%); $6.4 \%$ of responses were from outside of the U.S. and $10.5 \%$ of respondents did not provide their location. Level of education was distributed with $28.6 \%$ of the respondents having a 4-years college degree or less, $37.2 \%$ having a graduate or professional degree, and the remaining $34.2 \%$ having a doctorate degree. Most respondents indicated being employed full-time $(82.8 \%)$ as opposed to working part-time, being students, or contract workers.

\subsection{Procedure}

After consenting, respondents were asked "Does your job require you to use a workstation (e.g., desk, computer terminal, laptop) most of the day, and are you working (or have worked) from home due to COVID-19 or a stay-at-home mandate?" Only respondents who indicated "yes" to this question continued; others were told that they were not eligible for the study and thanked. Eligible respondents continued to complete the survey. Demographic measures included gender, age, location, and employment status and the other demographic control variables described below as "worker characteristics." Respondents reported their perceived level of productivity and indicated the difference in time spent at a workstation both compared to pre-pandemic levels. These two items served as our dependent variables of work outcome as described below. In addition, respondents answered numerous questions related to their workspace and their work context. All questions were optional. Upon reaching the end of the survey, respondents were thanked for their participation and asked to share a link to the anonymous survey with others who were working from home during the COVID-19 pandemic.

\subsection{Measures}

The survey comprised of multiple categories, with questions asking about the worker demographics, workspace characteristics, work conditions and a final category investigating the work performance and time spent at the workstation when work is performed from home during the pandemic period. First, worker characteristics were examined and used as control variables in our analyses. Second, respondents provided information related to the context of their physical workspace and how they conducted work within their new WFH situations. These context items were examined as independent variables in our analyses. Specifically, we examined individual and controlled multivariate contributions to two dependent variables that served as indicators of work performance during the pandemic's WFH period as compared to pre-pandemic work performance.

\subsubsection{Worker characteristics}

Multiple demographic characteristics were collected to describe our sample as reported above, as well as to serve as control variables in statistical analyses. In addition to those items already reported, respondents were also asked about their occupations. Occupational categories were provided as answer choices based on the occupational categories of the U.S. Bureau of Labor [48]. The full list of occupa- 
tional categories was reduced to the following general groups for analysis: business and office (receptionist, office manager, administrative assistant, etc.), engineering and architecture, education and arts, healthcare and social services, computer sciences and mathematics, basic scientists, and services and physical occupations. Respondents indicated their annual income from among four choices: less than $\$ 50 \mathrm{~K}$, between $\$ 50 \mathrm{~K}$ and $\$ 100 \mathrm{~K}$, between $\$ 100 \mathrm{~K}$ and $\$ 150 \mathrm{~K}$ and, more than $\$ 150 \mathrm{~K}$. Finally, respondents rated their overall physical and mental health status relative to their status before $\mathrm{WFH}$, using a 5-point Likert scale with 1 being much lower and 5 being much higher.

\subsubsection{Workspace context}

Workers indicated whether they had a dedicated space to conduct work in their homes, selecting from choices: "Yes, I have a dedicated room for work activities (e.g., home office, library, study)," "Yes, I have a dedicated workspace with other uses (e.g., kitchen, living room, bedroom)," and "No, I work in a variety of spaces, rooms, or locations around my home (e.g., couch, bed, dining table)." Respondents indicated if other people (e.g., family, roommates) were usually present in the same space while working and if they used any of the following items in their workspace: regular office desk, standing office desk, make-shift desk (e.g., table), adjustable office chair, non-adjustable chair, laptop/tablet computer, desktop computer, adjustable monitor, non-adjustable monitor, peripheral keyboard, peripheral mouse/trackpad, foot rest, document holder, natural light, task light, adjustable thermostat, local temperature control. Finally, we asked the workers to rate their level of satisfaction across multiple indoor environmental quality (IEQ) factors using a 5-point Likert scale, with 1 being extremely dissatisfied and 5 being extremely satisfied. Satisfaction with the visual environment was calculated as the average score of satisfaction with natural lighting, electric lighting and glare. Satisfaction with the thermal environment was calculated as the average satisfaction with the indoor air temperature and humidity. Satisfaction with air quality and noise were individually rated.

\subsubsection{Work context}

Respondents identified if they had adjusted their work schedule due to working at home by selecting either or both: "I now schedule my work hours around others" or "I have adjusted my work hours (ear- lier/later, switched days of week, shorter/longer)." The presence (yes) or absence (no) of other individuals or pets in the home were indicated across the following categories: independent adult (other than respondents themselves), dependent adult (e.g., special needs, geriatric care), teenage child (13-18), school-age child (6-12), toddler (2-5), infant $(<2$ years), pets (e.g., dogs, cats). Respondents indicated ways in which their home workspace was obtained selecting any responses that were true among the following choices: "I purchased new items for myself," "My employer purchased new items for me," "I brought items home from my office," and "I did not get anything new." We also asked respondents to rate their communication levels with their coworkers, their workload expectations or requirements, and distractions while working during the WFH period relative to their status before WFH. For these questions, a 5-point Likert scale was used with 1 being much lower and 5 being much higher.

\subsubsection{Work experience}

We examined two variables of interest relative to understanding changes in how work is conducted during WFH relative to pre-pandemic, in-office engagement: productivity and hours spent at a workstation on a typical workday. To assess productivity, respondents rated their productivity relative to the status before WFH using a 5-point Likert scale with 1 indicating much lower productivity, 3 indicating the same as before, and 5 indicating much higher productivity. Ratings for "relative productivity" were normally distributed around an average value of 2.90 $(\mathrm{SD}=1.16)$. Respondents provided an estimate of the duration of time they engaged at their workstation on a typical workday before and after WFH during the pandemic. Six choices were provided starting with the first choice as "less than 2 hours" and the sixth choice of "more than 10 hours," with an increment of 2 hours between each choice and its successor. The "change in time spent at a workstation" was calculated as the difference between the number of hours reported after WFH due to the pandemic from the hours reported before WFH. On average, the time spent at a workstation increased by 1.46 hours $(\mathrm{SD}=3.00)$ during WFH. A correlation analysis was conducted to test for any association between the two outcomes, finding very low association between relative productivity and change in time spent at a workstation $(r=0.12, N=962$, $p<0.001)$. 


\subsection{Data analysis}

We examined, in turn, the impact of the three types of predictor variables on our work performance outcomes (i.e., relative productivity and change in time spent at a workstation): worker characteristics, workspace context, and work context. For each type of predictors, we conducted descriptive analyses, followed by individual tests of each predictor using $t$-test and Pearson correlations. Finally, linear regression models were used to examine the individual predictors (within a type) against all other variables in terms of predicting unique variance in the two work performance outcomes. Specifically, within each regression model, we used: (1) the worker characteristic control variables as predictors, (2) the worker characteristic control variables and -in a second step- the workspace context variables as predictors, or (3) the worker characteristic control variables and -in a second stepthe work context variables as predictors. Within the regression models, dummy coding was used for all categorical variables. "Business and office" was used as the reference category for occupation because it was the most frequently selected, and "less than $\$ 50 \mathrm{~K}$ " served as the reference category for income because the median income for the U.S. falls in this category [48].

\section{Results}

\subsection{Worker characteristics}

Respondents had an average age of 40.90 years $(\mathrm{SD}=13.10$ years). Female workers accounted for $56.5 \%$ of the respondents, whereas $32.1 \%$ of respondents were male workers and the remaining $11.4 \%$ were missing or preferred not to say. Respondents primarily worked in occupations categorized as business and office (29.1\%), engineering and architecture $(24.6 \%)$, education and arts $(22.1 \%)$, followed by respondents in healthcare and social services $(9.3 \%)$, computer sciences and mathematics $(8.2 \%)$, basic scientists (4.2\%), and services and physical occupations $(2.6 \%)$. The largest percentage of respondents reported annual income between $\$ 50 \mathrm{~K}$ and $\$ 100 \mathrm{~K}$ (40.6\%), with the remaining respondents almost evenly distributed among the three remaining income levels: less than $\$ 50 \mathrm{~K}(19.0 \%), \$ 100 \mathrm{~K}-\$ 150 \mathrm{~K}$ (21.7\%), and more than $\$ 150 \mathrm{~K}(18.8 \%)$. The average physical health status was $(M=2.84, \mathrm{SD}=0.87)$ and the mental health status was $(M=2.70, \mathrm{SD}=0.93)$.
We first tested for any differences in productivity levels and difference in time spent at the workstation based on worker characteristics. There was a significant effect of gender on relative productivity (female $M=2.94, \mathrm{SD}=1.17$ vs. male $M=2.78, \mathrm{SD}=1.15$; $\mathrm{t}(864)=-1.97, p=0.050)$ but not on the change in time spent at the workstation (female $M=1.65$ hours (99 minutes), $\mathrm{SD}=2.95$ vs. male $M=1.37$ hours ( 82.2 minutes), $\mathrm{SD}=2.95 ; \mathrm{t}(851)=-1.33, p=0.181)$. Age correlated positively and minimally (albeit significantly) with relative productivity ( $r=0.12, N=746$, $p<0.001$ ), while the correlation between age and change in time spent at the workstation was not significant ( $r=0.06, N=736, p=0.122)$.

Mean and standard deviations for relative productivity and change in time at a workstation among the occupational categories and income levels are presented in Table 1. Significant differences across occupational categories were noted in both relative productivity $(\mathrm{F}(6,847)=3.28, p=0.003)$ and change in time spent at the workstation $(\mathrm{F}(6$, $835)=4.90, p<0.001)$. Post hoc comparisons using the Tukey HSD suggest that relative productivity was significantly lower for respondents with jobs in "engineering and architecture" $(M=2.74, \mathrm{SD}=0.08$, $p=0.011)$, "computer sciences and mathematics" $(M=2.77, \mathrm{SD}=0.14, p=0.032)$, and "healthcare and social services" $(M=2.70, \mathrm{SD}=0.13, p=0.026)$ as compared with increases reported by those in the "scientists" category $(M=3.50, \mathrm{SD}=0.2)$. Although workers across occupational categories all reported an increase in the time spent at a workstation after WFH, individuals with jobs in "healthcare and social services" $(M=2.63, \mathrm{SD}=0.33)$ reported a change in time that was significantly higher than those in "engineering and architecture" $(M=1.25, \mathrm{SD}=0.20$, $p=0.021)$ and "business and office" $(M=1.05$, $\mathrm{SD}=0.18, p=0.012$ ) categories. Individuals in the "business and office" category showed a significantly lower change in time at a workstation as compared to individuals in "education and arts" $(M=2.05$, $\mathrm{SD}=0.22, p=0.012$ ).

While no difference by income category was noted in the change in time spent at the workstation $(\mathrm{F}(3,764)=1.60, p=0.191)$, relative productivity differed across income levels $(\mathrm{F}(3,777)=3.47$, $p=0.021$ ). Post hoc analyses show that productivity was significantly lower for workers earning less than $\$ 50 \mathrm{~K}(M=2.64, \mathrm{SD}=0.10)$ than those earning $\$ 50 \mathrm{~K}-\$ 100 \mathrm{~K}(M=3.00, \mathrm{SD}=0.06, p=0.011)$ or $\$ 100 \mathrm{~K}-\$ 150 \mathrm{~K}(M=2.98, \mathrm{SD}=0.09, p=0.050)$. Finally, while workers' productivity significantly 
Table 1

Relative productivity and change in time spent at workstation compared to pre-pandemic levels by occupational categories and income

\begin{tabular}{lcc}
\hline & $\begin{array}{c}\text { Relative productivity } \\
{[1-5]}\end{array}$ & $\begin{array}{c}\text { Change in time at workstation, } \\
\text { hours per day }\end{array}$ \\
\hline Occupational categories & $3.00 \pm 0.07$ & $1.05 \pm 0.18$ \\
Business and office & $2.74 \pm 0.08$ & $1.25 \pm 0.20$ \\
Engineering, architecture & $2.94 \pm 0.08$ & $2.05 \pm 0.22$ \\
Education, arts & $2.77 \pm 0.14$ & $1.83 \pm 0.34$ \\
Computer sciences and mathematics & $2.70 \pm 0.13$ & $2.63 \pm 0.33$ \\
Healthcare and social services & $2.68 \pm 0.24$ & $0.57 \pm 0.63$ \\
Service and physical occupations & $3.50 \pm 0.20$ & $1.88 \pm 0.50$ \\
Scientists & & \\
Income & $2.64 \pm 0.10$ & $1.28 \pm 0.25$ \\
Less than $\$ 50 \mathrm{~K}$ & $3.00 \pm 0.06$ & $1.41 \pm 0.17$ \\
Between $\$ 50 \mathrm{~K}$ and $\$ 100 \mathrm{~K}$ & $2.98 \pm 0.09$ & $1.70 \pm 0.25$ \\
Between $\$ 100 \mathrm{~K}$ and $\$ 150 \mathrm{~K}$ & $2.84 \pm 0.10$ & \\
More than $\$ 150 \mathrm{~K}$ & & \\
\hline
\end{tabular}

Table 2

Effects of worker characteristics on relative productivity and change in time spent at a workstation while WFH

\begin{tabular}{|c|c|c|c|c|c|c|}
\hline \multirow[t]{2}{*}{ Worker characteristic variables } & \multicolumn{3}{|c|}{ Relative productivity } & \multicolumn{3}{|c|}{$\begin{array}{c}\text { Change in time at } \\
\text { workstation }\end{array}$} \\
\hline & $\mathrm{b}$ & SE & $p$-value & $\mathrm{b}$ & SE & $p$-value \\
\hline Gender & -0.17 & 0.09 & 0.059 & -0.14 & 0.25 & 0.584 \\
\hline Age & $0.01^{* *}$ & 0.01 & 0.005 & 0.01 & 0.01 & 0.163 \\
\hline Engineering, architecture & -0.10 & 0.11 & 0.321 & -0.23 & 0.28 & 0.416 \\
\hline Education, arts & -0.08 & 0.10 & 0.384 & 0.33 & 0.27 & 0.213 \\
\hline Computer sciences and mathematics & -0.16 & 0.13 & 0.230 & 0.38 & 0.36 & 0.295 \\
\hline Healthcare and social services & $-0.38^{* *}$ & 0.13 & 0.003 & $0.92^{* *}$ & 0.34 & 0.007 \\
\hline Service and physical occupations & -0.27 & 0.18 & 0.125 & -0.91 & 0.47 & 0.056 \\
\hline Scientists & 0.16 & 0.17 & 0.343 & 0.70 & 0.48 & 0.144 \\
\hline Between $\$ 50 \mathrm{~K}$ and $\$ 100 \mathrm{~K}$ & 0.07 & 0.06 & 0.299 & -0.21 & 0.17 & 0.229 \\
\hline Between $\$ 100 \mathrm{~K}$ and $\$ 150 \mathrm{~K}$ & 0.03 & 0.07 & 0.683 & 0.01 & 0.20 & 0.988 \\
\hline More than $\$ 150 \mathrm{~K}$ & -0.09 & 0.08 & 0.227 & 0.21 & 0.21 & 0.335 \\
\hline Physical health status & $0.11^{*}$ & 0.05 & 0.029 & 0.03 & 0.14 & 0.847 \\
\hline Mental health status & $0.36^{* * *}$ & 0.05 & $<0.001$ & $-0.30^{*}$ & 0.13 & 0.024 \\
\hline
\end{tabular}

positively correlated with both physical $(r=0.22$, $N=880, p<0.001)$ and mental health $(r=0.35$, $N=881, p<0.001)$ statuses, correlations between the change in time spent at the workstation and physical health $(r=-0.03, N=861, p=0.362)$ or mental health ( $r=-0.06, N=862, p=0.072)$ were not significant.

To answer our first research question, regression analysis was employed to understand the effect of workers characteristics on the WFH experience during the pandemic. The results suggest that worker characteristics, measured in this survey, significantly predicted respondents' relative productivity $\left(\mathrm{F}(13,720)=10.58, p<0.001, \mathrm{R}^{2}=0.16\right)$ and change in time spent at workstation $(\mathrm{F}(13,705)=2.31$, $\left.p=0.005, \mathrm{R}^{2}=0.10\right)$. Results for individual characteristics included in the model are presented in Table 2. Controlling for all the other worker characteristic variables, there was a significant difference in relative productivity between workers in the "healthcare and social services" and those in the reference of "business and office" $(b=-0.38$, $p=0.003)$. Age $(b=0.01, p=0.005)$, physical health status, $(b=0.11, p=0.029)$ and mental health status $(b=0.36, p<0.001)$ each uniquely predicted a significant increase in workers' productivity during the WFH period. A positive effect of working in the "healthcare and social services" also existed for change in time spent at a workstation $(b=0.92$, $p=0.007$ ), along with a negative effect of mental health status $(b=-0.30, p=0.024)$ once controlling for all the other worker characteristic variables.

\subsection{Workspace context}

Table 3 presents the mean, standard deviation (SD) of the continuous predictors, and the frequency and percentage of the categorical ones for the workspace context related variables. 
Table 3

Workspace context variables: Average/standard deviation and frequency/percentages for all predictors across the sample of valid responses for each item

\begin{tabular}{lcc}
\hline Categorical variables & Frequency & Percentage \\
\hline I have a dedicated room for work activities & 317 & 33.0 \\
I have a dedicated workspace with other uses & 483 & 50.3 \\
I work in variety of spaces, rooms, locations & 160 & 16.7 \\
Other people are present while I'm working & 447 & 47.6 \\
I have a regular office desk & 469 & 47.4 \\
I have a standing office desk & 56 & 5.7 \\
I have a make-shift desk & 431 & 43.6 \\
I have an adjustable office chair & 450 & 45.5 \\
I have a non-adjustable chair & 383 & 38.7 \\
I have a laptop/tablet computer & 860 & 87.0 \\
I have desktop computer & 222 & 22.4 \\
I have an adjustable monitor & 351 & 35.5 \\
I have a non-adjustable monitor & 186 & 18.8 \\
I have a peripheral keyboard & 419 & 42.4 \\
I have a peripheral mouse/trackpad & 549 & 55.5 \\
I have a footrest & 104 & 10.5 \\
I have a document holder & 126 & 12.7 \\
I have natural light (windows) & 808 & 81.7 \\
I have a task light & 339 & 34.3 \\
I have an adjustable thermostat & 445 & 45.0 \\
I have a local temperature control & 414 & 41.9 \\
\hline Continuous variables & Mean & Standard deviation \\
\hline Satisfaction with the visual environment & 3.93 & 0.83 \\
Satisfaction with the thermal environment & 4.00 & 1.06 \\
Satisfaction with air quality & 4.14 & 0.84 \\
Satisfaction with noise & 3.48 & 1.22 \\
\hline
\end{tabular}

An Analysis Of Variance (ANOVA) revealed a significant effect of the type of workspace on relative productivity $(\mathrm{F}(2,857)=3.49, p=0.031)$. Tukey HSD (Honestly Significant Test) tests showed that productivity for "I have a dedicated space for work activities" $(M=3.00, \mathrm{SD}=0.07)$ was significantly higher than that of "I work in a variety of places" $(M=2.69, \mathrm{SD}=0.09, p=0.021)$, but the "I have a dedicated space with other uses" ( $M=2.89$, $\mathrm{SD}=0.05)$ did not statistically differ from the other two conditions. There was also a significant omnibus effect on the difference in time spent at workstation $(\mathrm{F}(2,931)=3.40, p=0.032)$. Specifically, difference in time for the "I have a dedicated space for work activities" ( $M=1.75$ hours (105 minutes), $\mathrm{SD}=0.17$ ) was statistically higher than that of "I work in a variety of places" ( $M=0.98$ hours (59 minutes), $\mathrm{SD}=0.24$, $p=0.021)$, but the "I have a dedicated space with other uses" $(M=1.48, \mathrm{SD}=0.14)$ was not significantly different from the two other conditions.

An independent t-test revealed that workers who do not have other people present $(M=3.01, \mathrm{SD}=1.15)$ were significantly more productive than those who do have $(M=2.80, \mathrm{SD}=1.14 ; \mathrm{t}(841)=2.25, p=0.011)$. There was no difference in time spent at workstation based on whether respondents have people present while working or not $(\mathrm{t}(911)=0.21, p=0.846)$.

Differences in relative productivity and change in time spent at the workstation based on individual workspace components are presented in Table 4. Independent $t$-tests reveal that no item of equipment showed a significant relationship with worker productivity. On the other hand, having a regular desk $(\mathrm{t}(955)=-2.57, p=0.010)$ or an adjustable office chair $(\mathrm{t}(955)=-2.43, p=0.015)$ had a significant relationship with change in time spent at workstation. Specifically, workers who had a regular desk $(M=1.73$ hours (103 minutes), $\mathrm{SD}=2.90)$ or an adjustable office chair $(M=1.72$ hours (102 minutes), $\mathrm{SD}=3.00$ ) engaged more at their workstation compared with those who did not have such a desk $(M=1.23$ hours (74 minutes), $\mathrm{SD}=3.06)$ or an adjustable chair $(M=1.25$ hours (75 minutes), $\mathrm{SD}=2.97$ ). Finally, weak correlations were noted among satisfaction with the visual environment $(r=0.10, N=884, p=0.003)$, satisfaction with the thermal environment $(r=0.14, N=879$, $p<0.001)$, satisfaction with air quality $(r=0.07$, $N=881, p=0.034)$, satisfaction with noise $(r=0.09$, $N=877, p=0.008$ ) and relative productivity, and no 
Table 4

Relative productivity and change in time spent at workstation compared to pre-pandemic levels between workspace contexts

\begin{tabular}{|c|c|c|c|c|c|c|c|c|}
\hline & \multicolumn{4}{|c|}{ Relative productivity } & \multicolumn{4}{|c|}{ Change in time spent at workstation } \\
\hline & Yes & No & t-value & $\overline{p \text {-value }}$ & Yes & No & t-value & $p$-value \\
\hline I have a regular office desk & $2.87 \pm 1.14$ & $2.91 \pm 1.17$ & 0.48 & 0.631 & $1.73 \pm 2.90$ & $1.23 \pm 3.06$ & $-2.57^{*}$ & 0.010 \\
\hline I have a standing office desk & $3.04 \pm 1.05$ & $2.88 \pm 1.16$ & -0.95 & 0.340 & $2.18 \pm 3.02$ & $1.43 \pm 2.99$ & -1.79 & 0.073 \\
\hline I have a make-shift desk & $2.87 \pm 1.15$ & $2.90 \pm 1.15$ & 0.32 & 0.749 & $1.34 \pm 2.94$ & $1.57 \pm 3.03$ & 1.19 & 0.233 \\
\hline I have an adjustable office chair & $2.86 \pm 1.15$ & $2.91 \pm 1.15$ & 0.68 & 0.498 & $1.72 \pm 3.00$ & $1.25 \pm 2.97$ & $-2.43^{*}$ & 0.015 \\
\hline I have a non-adjustable chair & $2.89 \pm 1.15$ & $2.89 \pm 1.16$ & -0.02 & 0.985 & $1.41 \pm 2.89$ & $1.50 \pm 3.06$ & 0.49 & 0.623 \\
\hline I have a laptop/tablet computer & $2.88 \pm 1.15$ & $2.96 \pm 1.12$ & 0.73 & 0.462 & $1.53 \pm 2.99$ & $1.01 \pm 3.02$ & -1.76 & 0.079 \\
\hline I have desktop computer & $2.94 \pm 1.15$ & $2.87 \pm 1.15$ & -0.73 & 0.466 & $1.57 \pm 3.17$ & $1.44 \pm 2.94$ & -0.56 & 0.576 \\
\hline I have an adjustable monitor & $2.95 \pm 1.14$ & $2.86 \pm 1.16$ & -1.10 & 0.270 & $1.59 \pm 3.00$ & $1.40 \pm 2.96$ & -0.93 & 0.352 \\
\hline I have a non-adjustable monitor & $2.90 \pm 1.14$ & $2.89 \pm 1.16$ & -0.15 & 0.880 & $1.61 \pm 2.80$ & $1.43 \pm 3.04$ & -0.72 & 0.471 \\
\hline I have a peripheral keyboard & $2.85 \pm 1.18$ & $2.92 \pm 1.13$ & 0.87 & 0.383 & $1.65 \pm 3.07$ & $1.33 \pm 2.93$ & -1.63 & 0.103 \\
\hline I have a peripheral mouse/trackpad & $2.87 \pm 1.14$ & $2.91 \pm 1.17$ & 0.47 & 0.634 & $1.59 \pm 2.89$ & $1.31 \pm 3.11$ & -1.44 & 0.149 \\
\hline I have a footrest & $2.78 \pm 1.14$ & $2.90 \pm 1.15$ & 0.96 & 0.334 & $1.59 \pm 2.57$ & $1.45 \pm 3.04$ & -0.45 & 0.653 \\
\hline I have a document ho & $2.98 \pm 1.20$ & $2.88 \pm 1.14$ & -0.90 & 0.369 & $1.35 \pm 2.91$ & $1.49 \pm 3.00$ & 0.48 & 0.630 \\
\hline I have natural light (windows) & $2.90 \pm 1.14$ & $2.83 \pm 1.21$ & -0.68 & 0.497 & $1.51 \pm 2.93$ & $1.28 \pm 3.26$ & -0.93 & 0.353 \\
\hline I have a task light & $2.93 \pm 1.12$ & $2.86 \pm 1.17$ & -0.87 & 0.385 & $1.64 \pm 3.01$ & $1.38 \pm 2.99$ & -1.26 & 0.208 \\
\hline I have an adjustable thermostat & $2.93 \pm 1.13$ & $2.85 \pm 1.17$ & -1.08 & 0.280 & $1.53 \pm 3.04$ & $1.42 \pm 2.96$ & -0.56 & 0.572 \\
\hline I have a local temperature control & $2.93 \pm 1.15$ & $2.86 \pm 1.15$ & -0.96 & 0.335 & $1.41 \pm 2.94$ & $1.52 \pm 3.03$ & 0.55 & 0.581 \\
\hline
\end{tabular}

${ }^{* * *} p<0.001 .{ }^{* *} p<0.01 .{ }^{*} p<0.05$.

significant correlations existed between these parameters and change in time at the workstation.

To answer our second research question, regression models examining workspace context factors as predictors of relative productivity $(\mathrm{F}(37,687)=4.38$, $\left.p<0.001, \mathrm{R}^{2}=0.20\right)$ and change in time spent at workstation $\left(\mathrm{F}(37,672)=1.57, p=0.021, \mathrm{R}^{2}=0.03\right)$ were both significant (Table 5). While controlling worker characteristics and all other workspace variables, reporting of "I have a dedicated room for work activities" ( $b=0.16, p=0.020)$ uniquely predicted significantly higher relative productivity than before the WFH transition. In contrast, reporting "I work in a variety of spaces" $(b=-0.16, p=0.022)$ uniquely predicted significantly lower relative productivity. Despite low individual correlation to the outcome, once controlling for all other factors, satisfaction with the thermal environment predicted greater worker productivity $(b=0.12, p=0.024)$. No individual workspace variables were unique predictors of the difference in time spent at the workstation.

\subsection{Work context}

Table 6 presents the mean and standard deviation (SD) of the continuous predictors, and the frequency and percentage of the categorical predictors for the work context related variables, and Table 7 presents evaluation of differences in relative productivity and change in time spent at the workstation based on work context variables. Respondents who adjusted their work hours (earlier or later work schedule, switched days of week for work, shorter/longer) showed a significant increase $(\mathrm{t}(955)=-3.23, p<0.001)$ in time spent at the workstation $(M=1.65, \mathrm{SD}=3.01)$ compared to those who did not adjust their hours $(M=0.94, \mathrm{SD}=2.90)$. Furthermore, respondents who purchased new items for themselves showed a significantly higher change in time spent at the workstation $(M=1.88, \mathrm{SD}=2.96)$ compared with those who did not $(M=1.24, \mathrm{SD}=2.99)$.

Additional independent $t$-tests, presented in Table 7, revealed workers with at least one teenager living at home reported higher relative productivity $(M=3.10, \mathrm{SD}=1.15)$ than those without a teenager at home $(M=2.86, \mathrm{SD}=1.18 ; \mathrm{t}(644)=2.02, p=0.044)$, although both means hovered around the neutral response of 3.0. Respondents with school age children at home showed a significantly larger increase $(\mathrm{t}(721)=-2.02, p=0.044)$ in time spent at the workstation ( $M=1.97$ hours (118.2 minutes), $\mathrm{SD}=3.19)$, in comparison to those who do not have school age children at home $(M=1.42$ hours $(85.2 \mathrm{~min}-$ utes), $\mathrm{SD}=2.98$ ). Likewise, not having a toddler $(\mathrm{t}(692)=2.58, p=0.010)$ at home seemed to lessen the increase in time spent at the workstation during WFH: respondents with a toddler at home increased their hours at the workstation less $(M=0.76$ hours (45.6 minutes), $\mathrm{SD}=3.48$ ) than those without a toddler at home ( $M=1.58$ hours (94.8 minutes), $\mathrm{SD}=2.95)$. Finally, workers with an infant at home $(M=2.92, \mathrm{SD}=1.17)$ were significantly less productive than those without an infant at home $(M=2.39$, $\mathrm{SD}=1.37 ; \mathrm{t}(600)=-3.16, p=0.001)$, and respon- 
Table 5

Association of worker characteristics and workspace context with relative productivity and change in time spent at workstation compared to pre-pandemic levels

\begin{tabular}{|c|c|c|c|c|c|c|}
\hline \multirow[t]{2}{*}{ Variable } & \multicolumn{3}{|c|}{ Relative productivity } & \multicolumn{3}{|c|}{$\begin{array}{c}\text { Change in time spent at } \\
\text { workstation }\end{array}$} \\
\hline & $\mathrm{b}$ & $\mathrm{SE}$ & $p$-value & $\mathrm{b}$ & $\mathrm{SE}$ & $p$-value \\
\hline Gender & -0.18 & 0.09 & 0.059 & -0.29 & 0.25 & 0.256 \\
\hline Age & $0.01^{*}$ & 0.01 & 0.039 & 0.01 & 0.01 & 0.503 \\
\hline Engineering, architecture & -0.14 & 0.11 & 0.176 & -0.25 & 0.29 & 0.369 \\
\hline Education, arts & -0.06 & 0.10 & 0.550 & 0.34 & 0.27 & 0.214 \\
\hline Computer sciences and mathematics & -0.14 & 0.14 & 0.305 & 0.41 & 0.37 & 0.265 \\
\hline Healthcare and social services & $-0.38^{* *}$ & 0.13 & 0.004 & $0.98^{* *}$ & 0.35 & 0.005 \\
\hline Service and physical occupations & -0.21 & 0.18 & 0.246 & -1.03 & 0.48 & 0.102 \\
\hline Scientists & 0.24 & 0.18 & 0.183 & 0.63 & 0.48 & 0.189 \\
\hline Between $\$ 50 \mathrm{~K}$ and $\$ 100 \mathrm{~K}$ & 0.08 & 0.07 & 0.216 & -0.08 & 0.18 & 0.628 \\
\hline Between $\$ 100 \mathrm{~K}$ and $\$ 150 \mathrm{~K}$ & 0.03 & 0.07 & 0.730 & -0.07 & 0.20 & 0.719 \\
\hline More than $\$ 150 \mathrm{~K}$ & -0.11 & 0.08 & 0.183 & 0.15 & 0.22 & 0.469 \\
\hline Physical health status & $0.13^{*}$ & 0.05 & 0.017 & -0.05 & 0.15 & 0.702 \\
\hline Mental health status & $0.35^{* * *}$ & 0.05 & $<0.000$ & -0.21 & 0.14 & 0.125 \\
\hline I have a dedicated room for work activities & $0.16^{*}$ & 0.07 & 0.020 & 0.18 & 0.19 & 0.341 \\
\hline I work in a variety of spaces & $-0.16^{*}$ & 0.07 & 0.022 & -0.17 & 0.19 & 0.355 \\
\hline Other people are present while I'm working & 0.01 & 0.01 & 0.688 & 0.01 & 0.01 & 0.074 \\
\hline I have a regular office desk & -0.01 & 0.13 & 0.994 & 0.31 & 0.34 & 0.362 \\
\hline I have a standing office desk & -0.01 & 0.18 & 0.941 & 0.61 & 0.50 & 0.222 \\
\hline I have a make-shift desk & 0.02 & 0.12 & 0.895 & 0.12 & 0.32 & 0.717 \\
\hline I have an adjustable office chair & -0.06 & 0.13 & 0.629 & 0.28 & 0.35 & 0.423 \\
\hline I have a non-adjustable chair & 0.06 & 0.12 & 0.622 & 0.19 & 0.32 & 0.569 \\
\hline I have a laptop/tablet computer & -0.13 & 0.14 & 0.364 & 0.48 & 0.39 & 0.215 \\
\hline I have desktop computer & -0.07 & 0.12 & 0.554 & 0.10 & 0.33 & 0.762 \\
\hline I have an adjustable monitor & 0.08 & 0.11 & 0.459 & 0.31 & 0.29 & 0.299 \\
\hline I have a non-adjustable monitor & 0.04 & 0.12 & 0.697 & -0.11 & 0.32 & 0.742 \\
\hline I have a peripheral keyboard & 0.01 & 0.11 & 0.940 & -0.10 & 0.31 & 0.747 \\
\hline I have a peripheral mouse/trackpad & -0.04 & 0.11 & 0.704 & 0.11 & 0.29 & 0.722 \\
\hline I have a footrest & -0.17 & 0.14 & 0.207 & -0.12 & 0.36 & 0.734 \\
\hline I have a document holder & 0.08 & 0.13 & 0.528 & -0.49 & 0.35 & 0.158 \\
\hline I have natural light (windows) & 0.09 & 0.12 & 0.433 & -0.04 & 0.32 & 0.887 \\
\hline I have a task light & 0.05 & 0.09 & 0.531 & 0.20 & 0.25 & 0.417 \\
\hline I have an adjustable thermostat & -0.03 & 0.09 & 0.739 & 0.35 & 0.24 & 0.136 \\
\hline I have a local temperature control (fan, heater) & 0.05 & 0.08 & 0.541 & -0.27 & 0.23 & 0.244 \\
\hline Satisfaction with the visual environment & 0.02 & 0.06 & 0.367 & -0.36 & 0.15 & 0.732 \\
\hline Satisfaction with the thermal environment & $0.12^{*}$ & 0.05 & 0.024 & 0.05 & 0.15 & 0.736 \\
\hline Satisfaction with air quality & -0.05 & 0.07 & 0.457 & -0.08 & 0.19 & 0.677 \\
\hline Satisfaction with noise & -0.03 & 0.04 & 0.677 & -0.04 & 0.10 & 0.121 \\
\hline
\end{tabular}

${ }^{* * *} p<0.001 .{ }^{* *} p<0.01 .{ }^{*} p<0.05$.

dents with an infant in the home increased their hours at the workstation less $(M=0.64$ hours (38.4 minutes), $\mathrm{SD}=3.81)$ than those without an infant at home ( $M=1.53$ hours (94.8 minutes), $\mathrm{SD}=3.00$; $\mathrm{t}(661)=-2.15, p=0.032)$. Additional $t$-tests were conducted to analyze the effect of purchasing new items on productivity and change in time spent at the workstation. The respondents who purchased new items for themselves showed a significantly higher difference in time spent at the workstation $(M=1.88, \mathrm{SD}=2.96)$ compared with those who did not $(M=1.24, \mathrm{SD}=2.99)$.

We used correlations to evaluate the relationship between our outcome variables and the work context predictors that are continuous (i.e., communication with coworkers, workload expectations or requirements, and distractions while working). Communication with coworkers had a moderate positive association with relative productivity $(r=0.46$, $N=881, p<0.001)$, as did workload expectations $(r=0.32, N=882, p<0.001)$. In contrast, distractions while working was moderately negatively associated relative productivity $(r=-0.41, N=881$, $p<0.001)$. Although significant, distractions while working ( $r=-0.07, N=860, p=0.035)$ and communication with coworkers $(r=0.09, N=860, p=0.013$ ) had essentially no relationship to change in time spent at workstation. Only workload expectations 
Table 6

Work context variables: Average (SD) and frequency (\%) for all predictors across the sample of valid responses for each item

\begin{tabular}{lcc}
\hline Categorical variables & Frequency & Percentage \\
\hline I now schedule my work hours around others & 368 & 36.6 \\
I have adjusted my work hours & 722 & 73.4 \\
At least 1 independent adult lives with me & 816 & 84.2 \\
At least 1 dependent adult lives with me & 65 & 9.3 \\
At least 1 teenager lives with me & 136 & 18.8 \\
At least 1 school age child lives with me & 158 & 21.5 \\
At least 1 toddler lives with me & 110 & 15.6 \\
At least 1 infant lives with me & 63 & 9.4 \\
At least 1 pet lives with me & 408 & 50.2 \\
I purchased new items for myself & 342 & 34.6 \\
My employer purchased new items for me & 88 & 8.9 \\
I brought items home from my office & 302 & 30.5 \\
I did not get anything new & 424 & 42.9 \\
\hline Continuous variables & Mean & Standard deviation \\
\hline Communication with coworkers & 2.66 & 1.31 \\
Workload expectations or requirements & 3.25 & 1.03 \\
Distractions while working & 3.35 & 1.33 \\
\hline
\end{tabular}

Table 7

Relative productivity and change in time spent at workstation compared to pre-pandemic levels between work contexts

\begin{tabular}{|c|c|c|c|c|c|c|c|c|}
\hline & \multicolumn{4}{|c|}{ Relative productivity } & \multicolumn{4}{|c|}{ Change in time spent at workstation } \\
\hline & Yes & No & t-value & $p$-value & Yes & No & t-value & $p$-value \\
\hline how schedul & $2.84 \pm 1.27$ & $2.93 \pm 1.08$ & & 03 & $1.42 \pm 3.05$ & $1.48 \pm 2.96$ & 0.20 & 0.782 \\
\hline I have adjusted my work hours & $2.86 \pm 1.20$ & $3.00 \pm 1$ & 1.85 & 64 & $5 \pm$ & $0.94 \pm 2.90$ & $-3.23^{* * *}$ & $<0.001$ \\
\hline At least 1 independent adult lives with $\mathrm{r}$ & $2.89 \pm 1.15$ & $2.91 \pm 1$ & -0.17 & & $9 \pm$ & $1.18 \pm 2.75$ & & 0.253 \\
\hline t adult lives with me & $3.07 \pm 1.14$ & $2.87 \pm 1.19$ & & & $17 \pm 2$ & $1.48 \pm 3.05$ & & 0.095 \\
\hline At least 1 teenager lives with me & $3.10 \pm 1.15$ & $2.86 \pm 1.18$ & $2.02^{*}$ & 0.044 & $1.95 \pm 2.70$ & $1.40 \pm 3.10$ & $-1.93^{*}$ & 0.036 \\
\hline age child lives wi & $2.91 \pm 1.16$ & $2.88 \pm 1.19$ & -0.20 & 38 & $1.97 \pm 3.19$ & $1.42 \pm 2.98$ & $-2.02^{*}$ & 0.044 \\
\hline At least 1 to & $2.67 \pm 1.32$ & $2.92 \pm 1.17$ & -1.88 & 0.061 & $0.76 \pm 3.48$ & $1.58 \pm 2.95$ & $2.58^{* *}$ & 0.010 \\
\hline At least 1 infant lives with me & $2.39 \pm 1.37$ & $2.92 \pm 1.17$ & $-3.16^{* * *}$ & 0.001 & $0.64 \pm 3.81$ & $1.53 \pm 3.00$ & $-2.15^{*}$ & 0.032 \\
\hline At least 1 pet lives with me & $2.94 \pm 1.16$ & $2.81 \pm 1.17$ & 1.54 & & $1.57 \pm 3.14$ & $1.35 \pm 2.91$ & -1.07 & 0.224 \\
\hline I purc & $2.89 \pm 1.20$ & $2.89 \pm 1$ & -0.08 & & $1.88 \pm 2$ & $1.24 \pm 2.99$ & $-3.10^{* *}$ & 0.002 \\
\hline My en & $2.87 \pm 1.11$ & $2.89 \pm 1.16$ & 0.16 & 0.421 & $1.83 \pm 3.02$ & $1.42 \pm 2.99$ & -1.21 & 0.242 \\
\hline I brought items home from my office & $2.88 \pm 1.17$ & $2.90 \pm 1.14$ & 0.56 & 0.562 & $1.44 \pm 2.88$ & $1.47 \pm 3.05$ & 0.12 & 0.226 \\
\hline I did not get anything new & $2.89 \pm 1.14$ & $2.89 \pm 1.16$ & -0.01 & 0.513 & $1.29 \pm 3.10$ & $1.66 \pm 2.89$ & 1.90 & 0.462 \\
\hline
\end{tabular}

${ }^{* * *} p<0.001 .{ }^{* *} p<0.01 .{ }^{*} p<0.05$.

or requirements ( $r=0.21, N=860, p<0.001)$ had a weak positive association with change in time at the workstation.

The third research question was answered by two regression models examining work context variables as predictors of work performance outcomes were significant: relative productivity $(\mathrm{F}(29,444)=14.96$, $\left.p<0.001, \mathrm{R}^{2}=0.50\right)$ and change in time spent at workstation $\left(\mathrm{F}(29,439)=2.43, p<0.001, \mathrm{R}^{2}=0.14\right)$. The results are presented in Table 8 . Controlling for the other variables, communication with coworkers uniquely predicted higher relative productivity $(b=0.26, p<0.001)$, as did workload expectations $(b=0.30, p<0.001)$. In contrast, in this multiple regression, distractions while working $(b=-0.26$, $p<0.001)$ and having an infant at home $(b=-0.61$, $p=0.001)$ both independently predicted lower relative productivity. Likewise, adjusting work hours (starting earlier/later, switching days of week, having shorter/longer workdays) uniquely predicted larger increases in change in the time at the workstation ( $b=0.81, p=0.012$ ), as did workload expectations $(b=0.40, p=0.003)$. Finally, distractions while working also independently predicted smaller differences in hours at the workstation $(b=-0.24, p=0.031)$.

\section{Discussion}

This study showed that overall productivity level of office workers did not change during the WFH experience due to the stay-at-home orders relative to their 
Table 8

Associations among worker characteristics and work context with relative productivity and change in time spent at workstation compared to pre-pandemic levels

\begin{tabular}{|c|c|c|c|c|c|c|}
\hline \multirow[t]{2}{*}{ Variable } & \multicolumn{3}{|c|}{ Relative productivity } & \multicolumn{3}{|c|}{$\begin{array}{l}\text { Change in time spent at } \\
\text { workstation }\end{array}$} \\
\hline & $\mathrm{b}$ & SE & $p$-value & $\mathrm{b}$ & SE & $p$-value \\
\hline Gender & -0.11 & 0.09 & 0.219 & -0.51 & 0.30 & 0.095 \\
\hline Age & 0.01 & 0.01 & 0.339 & 0.01 & 0.01 & 0.574 \\
\hline Engineering, architecture & -0.10 & 0.10 & 0.352 & -0.25 & 0.35 & 0.472 \\
\hline Education, arts & 0.01 & 0.10 & 0.991 & -0.03 & 0.34 & 0.915 \\
\hline Computer sciences and mathematics & -0.15 & 0.14 & 0.315 & 0.49 & 0.47 & 0.306 \\
\hline Healthcare and social services & -0.11 & 0.13 & 0.400 & $0.96^{*}$ & 0.43 & 0.028 \\
\hline Service and physical occupations & -0.27 & 0.17 & 0.114 & $-1.52^{*}$ & 0.55 & 0.007 \\
\hline Scientists & 0.24 & 0.17 & 0.170 & 0.26 & 0.58 & 0.642 \\
\hline Between $\$ 50 \mathrm{~K}$ and $\$ 100 \mathrm{~K}$ & -0.04 & 0.06 & 0.500 & -0.14 & 0.21 & 0.512 \\
\hline Between $\$ 100 \mathrm{~K}$ and $\$ 150 \mathrm{~K}$ & 0.02 & 0.07 & 0.742 & 0.15 & 0.24 & 0.528 \\
\hline More than $\$ 150 \mathrm{~K}$ & 0.02 & 0.08 & 0.788 & -0.01 & 0.27 & 0.954 \\
\hline Physical health status & 0.05 & 0.05 & 0.310 & -0.05 & 0.18 & 0.753 \\
\hline Mental health status & $0.25^{* * *}$ & 0.05 & $<0.001$ & -0.23 & 0.17 & 0.181 \\
\hline I now schedule my work hours around others & -0.08 & 0.09 & 0.397 & -0.21 & 0.32 & 0.498 \\
\hline I have adjusted my work hours & -0.01 & 0.09 & 0.970 & $0.81^{*}$ & 0.32 & 0.012 \\
\hline At least 1 independent adult lives with me & 0.01 & 0.10 & 0.883 & 0.09 & 0.34 & 0.794 \\
\hline At least 1 dependent adult lives with me & 0.25 & 0.17 & 0.148 & 0.74 & 0.59 & 0.210 \\
\hline At least 1 teenager lives with me & 0.06 & 0.13 & 0.624 & 0.57 & 0.44 & 0.202 \\
\hline At least 1 school age child lives with me & -0.12 & 0.13 & 0.384 & 0.59 & 0.45 & 0.187 \\
\hline At least 1 toddler lives with me & 0.024 & 0.15 & 0.874 & -0.32 & 0.50 & 0.525 \\
\hline At least 1 infant lives with me & $-0.61^{* *}$ & 0.17 & 0.001 & -0.72 & 0.57 & 0.211 \\
\hline At least 1 pet lives with me & 0.01 & 0.08 & 0.956 & 0.11 & 0.28 & 0.689 \\
\hline I purchased new items for myself & -0.120 & 0.12 & 0.323 & 0.34 & 0.39 & 0.384 \\
\hline My employer purchased new items for me & 0.034 & 0.16 & 0.838 & -0.72 & 0.55 & 0.192 \\
\hline I brought items home from my office & -0.02 & 0.11 & 0.867 & 0.04 & 0.36 & 0.895 \\
\hline I did not get anything new & -0.19 & 0.13 & 0.164 & -0.17 & 0.45 & 0.701 \\
\hline Communication with coworkers & $0.26^{* * *}$ & 0.03 & $<0.001$ & 0.20 & 0.11 & 0.068 \\
\hline Workload expectations or requirements & $0.30^{* * *}$ & 0.04 & $<0.001$ & $0.40^{* *}$ & 0.13 & 0.003 \\
\hline Distractions while working & $-0.26^{* * *}$ & 0.03 & $<0.001$ & $-0.24^{*}$ & 0.11 & 0.031 \\
\hline
\end{tabular}

${ }^{* * *} p<0.001 .{ }^{* *} p<0.01 .{ }^{*} p<0.05$.

productivity before the pandemic. However, workers indicated a dramatic increase in the number of hours spent at a workstation by 1.46 hours, approximately 90 minutes, during a typical WFH day. This section provides a discussion of the theoretical and practical implications relative to worker characteristics, workspace context and work context on our two work performance outcomes.

\subsection{Theoretical implications}

\subsubsection{Worker characteristics}

Overall, female workers, older workers, and those at higher income levels were found to be significantly more productive than their counterparts while WFH during the pandemic. The relationship of age and higher income has been demonstrated in previous research [49], and the literature shows that women are more inclined towards remote work than male workers and perceive more benefits and less barriers of WFH, which boosts their productivity in comparison to the typical work from office $[50,51]$. Men are increasingly putting more effort into household duties [52], but women continue to endure the largest portion of the housework especially when it comes to childcare [53]. WFH has allowed female workers to create the much-needed balance between work-family-home responsibilities. Specifically, Colley and Williamson [54] found that women working from home during the pandemic showed a better integration of work-family responsibilities, which allowed them to be more productive. Further examination of evolving gender roles relative to WFH and the work-family-home responsibilities can assist in understanding how these roles and relationship intersect to support positive work performance and work well-being. Similarly, additional research is recommended to further investigate the effect of age on the WFH experience, especially among elderly who might not be as familiar with the remote technology as younger workers [55]. 
Our data suggest that workers in the "scientists" category showed the highest productivity levels in comparison to "engineering and architecture," "computer sciences and mathematics" and "healthcare and social services." It is likely that "scientists" might have more flexibility to WFH as some of their work does not require them to be physically present at their workplaces. Our results also suggest that "healthcare and social services" and "education and arts" workers are spending more time at their workstations during the pandemic compared to other occupational categories where workers who are spending the same time as before. Such a finding can be attributed to increased use of telemedicine for providing healthcare services [56] and remote learning classrooms in educational settings [57] as opposed to in-person clinical visits or educational sessions. Alternatively, workers with typical office jobs (receptionist, office manager, administrative assistant, etc.) did not witness a major shift in their time spent at the workstation. These data highlight the importance of examining more than just productivity but understanding how transitioning to a WFH model can differentially affect how workers engaging in their work across different occupations. Our findings highlight a few occupational categories that may be at most risk for disruption in their work patterns and eventual health and well-being should WFH continue in the future, namely healthcare [58] and education [59].

Beyond demographic and work characteristics, our results also demonstrate that workers' productivity was related to better physical and mental health statuses, which is aligned with prior work. For instance, Singh et al. [60] showed that physical symptoms such as asthma and allergies negatively affected 16 work hours per month. Similarly, the number of work hours affected negatively by mental symptoms such as depression and anxiety reached 20 hours per month. Furthermore, it is postulated that poor mental and physical health statuses can deteriorate workers' productivity in the form of "absenteeism" (through sick leaves) and "presenteeism" (not fully functioning) [61]. The health status of workers working from home is gaining additional attention [12] and researchers should investigate ways to promote healthy work conditions and proper means to balance between work and well-being.

\subsubsection{Workspace context}

Our results suggest that productivity levels were higher for workers who have a dedicated workspace at home in comparison to those who do not have a dedicated workspace. Previous research studies about WFH have recommended that workers create their own home work area and recognize it as their workspace [62], which would help workers mentally shift from the home to the work atmosphere, reduce distractions and improve their productivity and performance. In fact, the lack of a dedicated workspace when working from home can disrupt the work experience, increase family-work conflicts and degrade worker productivity [63].

Our results also suggest that sharing the workspace with another household member decreases the worker's productivity. The literature on the relation between the office type and productivity is split: while some research studies show that a private office increases the worker's productivity in comparison to open plan offices, others support that an open plan layout is better in terms of productivity [64]. In the case of WFH, the home-work environment might be dramatically different than the open plan offices where workers share the workspace with coworkers. For example, during the pandemic's WFH period, workers might be sharing their workspaces with their children who are attending online classes and might be disrupted frequently, which could hamper productivity [65]. To that end, future research directions should investigate whether sharing the workstation or workspace with a child have the same impact as sharing it with another working adult.

Furthermore, we found that the satisfaction with IEQ parameters, especially the thermal environment, and having a dedicated workspace were positively associated with productivity, while having a desk and adjustable chair were associated with increased time spent at the workstation. The literature provides a wide variety of studies that are consistent with these findings. For instance, Geng et al. [66] showed that thermal satisfaction increases office workers' productivity while postulating that it is the most influential IEQ parameter affecting productivity. Other studies also showed that satisfaction with the indoor air quality [67], lighting [68], and noise [69] boost workers productivity. Similarly, having a dedicated workspace that is not intended for other uses decreases the probability of workers being interrupted by distractions, and that having a dedicated desk and adjustable chair may result in increased comfort allowing workers to spend more hours at their workstations. Importantly, owning an adjustable chair can reduce musculoskeletal risk [70], which in can increase workers engagement at the workstation. We found that workers that purchased their own 
equipment also reported being at their workstations for more hours than before the pandemic. This points to an awareness by the workers regarding the need for a supportive workplace and illuminates the importance of organizations ensuring the workers have the necessary workstation set-up to support WFH.

\subsubsection{Work context}

Multiple different associations were noted relative to the type of children present in the WFH context. Workers who had an infant at home had lower productivity levels, likely resulting from high-level of on-going attention required in infant care that can become a major distraction for WFH workers [71]. On the other hand, having a teenager boosted productivity; a possible reason could be that teenagers are more independent and able to help with household tasks and even take care of younger siblings allowing workers to focus more on their jobs, reducing distractions. Schieman et al. [72] found that having a teenager at home during the COVID-19 era did not impact the work of parents and did not contribute to the work-life conflict workers might witness during WFH. Workers with toddlers and infants spent less time at their workstation compared to before the pandemic and those with school-age children had increased time at their workstation. School-age children require constant attention from their parents to make sure that they are following up with schoolwork; thus, WFH parents tend to allow their children to share their workstations while working to keep an eye on them [73], which could lead to increased time at the workstation. On the other hand, having toddlers and infants forces the workers to leave their workstation more frequently to care for their children.

Beyond interpersonal relations within the home, our findings indicate that more communication with coworkers and higher workload expectations were associated with higher worker productivity. Another recent study has also demonstrated that workers who maintain frequent and effective communication with their coworkers tend to perform better during the WFH period [74]. With the positive effect of communication on workers' productivity, it is important to identify the most useful communication technologies to support WFH and to further understand factors influencing successful implementation of these technologies, such as degree of trust and reliability. The sudden shift to WFH during the pandemic made some employers feel insecure about their businesses which pushed them to increase their expectations from their workers -maybe unintentionally-[75]. Thus, a reasonable conclusion for the positive relationship between productivity and workload expectations, is that workers are working harder, putting more effort into their work and showing higher productivity levels in order to meet the employer expectations [76], and to prove they can perform well even under extreme and unexpected conditions [77]. However, distractions while WFH were a major cause for degraded productivity. Workers at home are susceptible to all kinds of interruptions while remotely working (e.g., take care of children, completing household tasks, sharing the workspace with others, etc.) which would negatively affect their productivity and in most cases oblige them to pause their tasks [65].

\subsection{Practical implications}

Increased WFH arrangements will likely be a reality beyond the COVID-19 pandemic. Conclusions from this study provide an nuanced understanding of how the WFH experience can impact work performance, which provides employers, employees, and other supporting professionals (e.g., ergonomists, therapists) with information relative to the key considerations for how to mitigate factors that might degrade performance. Importantly, our findings indicate that better physical and mental health statuses were associated with improved productivity, highlighting the need to develop supportive policies and practices targeted to key worker and work characteristics that will assist in balancing performance and well-being in the WFH context. For example, in our data, older, higher-income, and female workers demonstrated higher productivity levels compared to their counterparts, which highlights types of workers who may require increased supports through organizational policies and practices to promote successful WFH (e.g., younger, lower-income, male). These findings are similar to other recent reports published by the Pew Research Center noting that older workers did not find the transition to WFH during the pandemic as difficult as younger workers [78], and workers with low income levels faced more financial distress compared to those earning high income levels [79].

In addition to worker characteristics, our results provide employers and other professionals with information related to the way in which work is conducted and the space where work is completed when WFH. For example, communication with coworkers was associated with increased productivity levels 
which indicates the necessity for organizations to identify communication tools that can foster collaboration during remote work. Additionally, our findings inform recommendations to establish the WFH workstation to improve work performance, which includes identifying a dedicated space for work purposes, isolating the worker from other individuals in the household, and creating an environment with optimal thermal conditions to boost performance. These data illuminate potential equity issues, as many workers may not have the capability or resources necessary to create an ideal WFH environment. These issues must be considered and addressed through policies, practices, and supports as organizations consider widespread adoption of WFH practices.

Finally, our results indicate a shift in the way in which workers are engaging in their work; specifically, that workers are spending approximately 90 additional minutes engaging at their office workstations as part of their workday. Prior to the pandemic, musculoskeletal pain was among the most widespread health issues threatening office workers [80]. On a positive note, our results indicated that workers who spent more time at their workstation tended to own an office desk or an adjustable chair. With WFH likely resulting in more time spent at the workstation than when working in the office setting, organizations should prioritize support for an ergonomic set up of home workstations. Furthermore, we also found that increased time at the workstation was associated with shifts in the way work hours were scheduled, and decreased time at the workstation was reported when there was an infant or a toddler at home. Employers and supporting professionals must be sensitive to individual employee needs or desires to shift work patterns to support work-family balance, develop methods to monitor employee performance and well-being relative to any shifts in work patterns, and identify policies, practices, or supports that will ensure successful re-organization of work patterns to promote positive WFH experiences.

\subsection{Limitations}

Multiple limitations must be considered when interpreting the findings in this study. Firstly, caution should be used in generalizing the results of this study. The vast majority of respondents to this survey were from the U.S., and nearly half of the respondents were from California. In addition, although respondents were well distributed across income categories, our overall sample had a relatively high income as compared to the median income level in the U.S., which is below $\$ 50 \mathrm{~K}$. Moreover, our sample also had a much larger proportion of the respondents having college or graduate degrees than typical across all people in the U.S. Secondly, productivity in this study was measured relative to the productivity prior to work from home experience due to the pandemic. Slight variations up and down may or may not result in meaningful changes in the context of the actual job performance. Finally, the change in time spent at the workstation does not necessarily equate to overall increase in work hours, but is an indication that the workers are spending more time at their workstations when WFH than when conducting work at their place of employment.

\subsection{Future research directions}

Further research is needed to study the specific effects of WFH on gender inequalities both at home and at work. Along those lines, additional research is also needed to examine the effect of family-work conflicts and the mechanisms used by workers to cope with distractions caused by other family members and daily home tasks. Furthermore, it is necessary to investigate the role of communication technology on the WFH experience and to understand the practical and social implications of relying on digital technologies to perform WFH. In addition, future research is needed to continue investigating the feasibility of WFH across different work categories and what role technology plays in enabling successful transitions to different occupations. Finally, the health status of workers working from home should be given additional attention and researchers should investigate ways to promote healthy work conditions and proper means to balance between work and well-being.

\section{Conclusion}

With the spread of the novel SARS-CoV2 virus, most office workers were obliged to shift to remote working almost overnight in mid-March 2020, and the adoption of WFH strategies is likely to persist beyond the pandemic. This work investigated the worker experience during the pandemic's WFH period and focused on two outcomes: relative productivity and the change in time spent at the workstation at a typical workday. Overall, the results suggest that workers' productivity levels did not change 
due to the remote work transition, but that higher productivity was associated with better mental and physical health status. Several worker characteristics, workspace, and work contexts were found to be associated with increased and decreased productivity. Specifically, female workers, older workers, and high-waged workers showed higher productivity levels. Effective communication with coworkers, satisfaction with the thermal environment, workload expectations, having a teenager at home, not having an infant at home, and establishing a dedicated workspace for work activities that has no other uses were all associated with higher productivity. In addition to impacts on productivity, study data indicated that there was an increase in the number of hours spent at the workstation by approximately 1.5 hours on a typical WFH day in comparison to a workday before the pandemic. Longer hours spent at the workstation were associated with having a school-age child at home, having a desk or an adjustable chair at the workstation, and adjustment of specific work hours. The findings of this work highlight key considerations for organizational policies and practices that employers, employees, and other worker support professional can use as a foundation for planning productive and healthy design of WFH in the future of work.

\section{Acknowledgments}

This material is based upon the work supported by the National Science Foundation under Grant No. 1763134 and by the Army Research Office and was accomplished under Cooperative Agreement Number W911NF-20-2-0053. Any opinions, findings, and conclusions or recommendations expressed in this material are those of the authors and do not necessarily reflect the views of the National Science Foundation and should not be interpreted as representing the official policies, either expressed or implied, of the Army Research Office or the U.S. Government. The U.S. Government is authorized to reproduce and distribute reprints for Government purposes notwithstanding any copyright notation herein.

\section{Conflict of interest}

None to report.

\section{References}

[1] Gostin LO, Wiley LF. Governmental public health powers during the COVID-19 pandemic: stay-at-home orders, business closures, and travel restrictions. Jama. 2020 Jun 2;323(21):2137-8.

[2] Brynjolfsson E, Horton JJ, Ozimek A, Rock D, Sharma G, TuYe HY. COVID-19 and remote work: an early look at US data, 2020.

[3] Abbott-Gaffney C, Jacobs K. Telehealth in school-based practice: Perceived viability to bridge global OT practitioner shortages prior to COVID-19 global health emergency. Work. 2020;1-7.

[4] Park S, Grosser TJ, Roebuck AA, Mathieu JE. Understanding work teams from a network perspective: A review and future research directions. Journal of Management. 2020 Jul;46(6):1002-28.

[5] Messenger J. Working time and the future of work., ILO Futur. Work Res. Pap. Ser., 2018.

[6] Nakrošienè A, Bučiūnienè I, Goštautaitè B. Working from home: characteristics and outcomes of telework. Int J Manpow. 2019.

[7] Bloom N, Liang J, Roberts J, Ying ZJ. Does working from home work? Evidence from a Chinese experiment. Q J Econ. 2015 Feb 1;130(1):165-218.

[8] Golden TD, Veiga JF, Simsek Z. Telecommuting's differential impact on work-family conflict: Is there no place like home? J Appl Psychol. 2006 Nov;91(6):1340.

[9] Lapierre LM, Van Steenbergen EF, Peeters MC, Kluwer ES. Juggling work and family responsibilities when involuntarily working more from home: A multiwave study of financial sales professionals. J Organ Behav. 2016 Aug;37(6):804-22.

[10] Kim J, De Dear R. Workspace satisfaction: The privacycommunication trade-off in open-plan offices. J Environ Psychol. 2013, pp. 18-26.

[11] Greenhaus JH, Allen TD. Work-family balance: A review and extension of the literature., 2011.

[12] Xiao Y, Becerik-Gerber B, Lucas G, Roll SC. Impacts of working from home during COVID-19 pandemic on physical and mental well-being of office workstation users. J Occup Environ Med. 2021 Mar;63(3):181.

[13] Cook D. The Global Remote Work Revolution and the Future of Work., in The Business of Pandemics: The COVID-19 Story, 2020.

[14] Santana M, Cobo-Martín MJ. What is the future of work? A science mapping analysis. Eur Manag J. 2020.

[15] Livingston BA. Bargaining behind the scenes: Spousal negotiation, labor, and work-family burnout. J Manage. 2014 May;40(4):949-77.

[16] Feng Z, Savani K. Covid-19 created a gender gap in perceived work productivity and job satisfaction: implications for dual-career parents working from home. Gend Manag An Int J. 2020.

[17] Shockley KM, Shen W, DeNunzio MM, Arvan ML, Knudsen EA. Disentangling the relationship between gender and work-family conflict: An integration of theoretical perspectives using meta-analytic methods. J Appl Psychol. 2017.

[18] Bönte W, Krabel S. You can't always get what you want: Gender differences in job satisfaction of university graduates. Appl Econ. 2014 Jul 23;46(21):2477-87.

[19] Feyrer J. Aggregate evidence on the link between age structure and productivity. Popul Dev Rev. 2008 Jan 1;34: 78-99. 
[20] Roosaar L, Masso J, Varblane U. Age-related productivity decrease in high-waged and low-waged employees. Int $\mathbf{J}$ Manpow. 2019.

[21] Gorlick ADAM. The productivity pitfalls of working from home in the age of COVID-19, Stanford News, 2020.

[22] Choudhury P, Foroughi C, Larson B. Work from Anywhere Or Co-locate?: Autonomy Versus Learning Effects at the United States Patent Office, 2018.

[23] Bryant G, Maintaining Young Lawyer Well-Being in a Pandemic, 2020.

[24] Lerner D, Amick III BC, Lee JC, Rooney T, Rogers WH, Chang H, Berndt ER. Relationship of employee-reported work limitations to work productivity. Med Care. 2003 May 1:649-59.

[25] Goetzel RZ, Long SR, Ozminkowski RJ, Hawkins K, Wang S, Lynch W. Health, absence, disability, and presenteeism cost estimates of certain physical and mental health conditions affecting US employers. J Occup Environ Med. 2004 Apr 1;46(4):398-412.

[26] Fassoulis K, Alexopoulos N. The workplace as a factor of job satisfaction and productivity. J Facil Manag. 2015.

[27] Soriano A, Kozusznik MW, Peiró JM, Demerouti E. Employees' Work Patterns-Office Type Fit and the Dynamic Relationship Between Flow and Performance. Appl Psychol. 2020.

[28] Moretti A, Menna F, Aulicino M, Paoletta M, Liguori S, Iolascon G. Characterization of Home Working Population during COVID-19 Emergency: A Cross-Sectional Analysis. Int J Environ Res Public Health, 2020.

[29] Lopez-Leon S, Forero DA, Ruiz-Díaz P. Recommendations for working from home during the COVID-19 pandemic (and beyond). Work. 2020 Jan 1;66(2):371-5.

[30] Suart C, Suart TN, Graham K, Truant R. When the Labs Closed: Graduate Students' and Postdoctoral Fellows' Experiences of Disrupted Research During the COVID-19 Pandemic, 2020. [Online]. Available: https://doi.org/10.21203/rs.3.rs-59050/v1\%0D

[31] Kim J, Candido C, Thomas L, de Dear R. Desk ownership in the workplace: The effect of non-territorial working on employee workplace satisfaction, perceived productivity and health. Build Environ. 2016 Jul 1;103:203-14.

[32] Rudnicka A, Newbold JW, Cook D, Cecchinato ME, JJ S. Eworklife: developing effective strategies for remote working during the COVID-19 pandemic. In Eworklife: developing effective strategies for remote working during the COVID-19 pandemic., New Futur. Work Online Symp., 2020.

[33] Awada M, Srour I. A genetic algorithm based framework to model the relationship between building renovation decisions and occupants' satisfaction with indoor environmental quality. Build Environ. 2018 Dec 1;146:247-57.

[34] Kang S, Ou D, Mak CM. The impact of indoor environmental quality on work productivity in university open-plan research offices. Build Environ. 2017 Nov 1;124: 78-89.

[35] Kim J, De Dear R. Nonlinear relationships between individual IEQ factors and overall workspace satisfaction. Build Environ. 2012 Mar 1;49:33-40.

[36] Chen CF, et al. The impacts of building characteristics, social psychological and cultural factors on indoor environment quality productivity belief. Build Environ. 2020.
[37] Heschong L, Mahone D. Windows and offices: A study of office worker performance and the indoor environment. 2003.

[38] Nawaz A, Javed A, Raja UM. Impact of workspace design on employee's productivity: a case study of public sector universities in Hazara division. Int J Sustain Real Estate Constr Econ. 2019;1(3):201-14.

[39] Pastore L, Andersen M. Building energy certification versus user satisfaction with the indoor environment: Findings from a multi-site post-occupancy evaluation (POE) in Switzerland. Build Environ. 2019 Mar 1;150:60-74

[40] Hunter EM, Clark MA, Carlson DS. Violating work-family boundaries: Reactions to interruptions at work and home. J Manage. 2019, pp. 1284-1308.

[41] Shaffer MA, Joplin JR, Hsu YS. Expanding the boundaries of work-family research: A review and agenda for future research. Int J Cross Cult Manage. 2011 Aug;11(2): 221-68.

[42] DeFilippis E, Impink SM, Singell M, Polzer JT, Sadun R. Collaborating During Coronavirus: The Impact of COVID19 on the Nature of Work, 2020.

[43] Alon TM, Doepke M, Olmstead-Rumsey J, Tertilt M. The impact of COVID-19 on gender equality, 2020.

[44] Singh J, Flaherty K, Sohi RS, Deeter-Schmelz D, Habel J, Le Meunier-FitzHugh K, Malshe A, Mullins R, Onyemah V. Sales profession and professionals in the age of digitization and artificial intelligence technologies: concepts, priorities, and questions. J Pers Sell Sales Manag. 2019 Jan 2;39(1):22.

[45] Peasley MC, Hochstein B, Britton BP, Srivastava RV, Stewart GT. Can't Leave it at Home? The Effects of Personal Stress on Burnout and Salesperson Performance. J Bus Res. 2020.

[46] Balkeran A, Hustle Culture and the Implications for Our Workforce, 2020.

[47] Obrenovic B, Du J, Godinic D, Tsoy D, Khan MAS, Jakhongirov I. Sustaining enterprise operations and productivity during the COVID-19 pandemic: 'Enterprise Effectiveness and Sustainability Model,' Sustainability, 2020.

[48] U.S. Bureau of Labor Statistics., 2018 Standard Occupational Classification System, 2020. https://www.bls.gov/ soc/2018/major_groups.htm.

[49] Cardoso AR, Guimarães P, Varejão J. Are older workers worthy of their pay? An empirical investigation of ageproductivity and age-wage nexuses. Economist (Leiden)., 2011.

[50] Pérez MP, de Luis Carnicer MP, Sśanchez AM. Differential effects of gender on perceptions of teleworking by human resources managers. Women Manag Rev. 2002.

[51] Madan N, Mani D, Pillutla M. The Impact of Job Need for Human Proximity and Communication Technologies on Remote Work Efficacy, SSRN, 2020.

[52] Miller AJ, Carlson DL. Great expectations? Working-and middle-class cohabitors' expected and actual divisions of housework. J Marriage Fam. 2016 Apr;78(2):346-63.

[53] Cerrato J, Cifre E. Gender inequality in household chores and work-family conflict. Front Psychol. 2018.

[54] Colley L, Williamson CDS. Working during the Pandemic: From resistance to revolution?, 2020.

[55] Leonardi C, Mennecozzi C, Not E, Pianesi F, Zancanaro M. Designing a familiar technology for elderly people. Gerontechnology. 2008 Jun;7(2):151. 
[56] Conforti C, et al. Impact of the COVID-19 Pandemic on Dermatology Practice Worldwide: Results of a Survey Promoted by the International Dermoscopy Society (IDS)., Dermatol. Pract. Concept., 2021.

[57] Abbasi MS, et al. E-Learning perception and satisfaction among health sciences students amid the COVID-19 pandemic., Work, 2020, pp. 1-8.

[58] Krueger CA, et al. COVID Will End But Telemedicine May be Here to Stay. J Arthroplasty, 2021.

[59] Ali W. Online and remote learning in higher education institutes: A necessity in light of COVID-19 pandemic. High Educ Stud. 2020;10(3):16-25.

[60] Singh A, Syal M, Grady SC, Korkmaz S. Effects of green buildings on employee health and productivity. Am J Public Health. 2010 Sep;100(9):1665-8.

[61] Al Horr Y, Arif M, Kaushik A, Mazroei A, Katafygiotou M, Elsarrag E. Occupant productivity and office indoor environment quality: A review of the literature. Build Environ. 2016.

[62] Songsangyos P, Iamamporn S. Remote Working with Work-life Balance. Int J Appl Comput Technol Inf Syst., 2020.

[63] Donnelly N, Proctor-Thomson SB. Disrupted work: homebased teleworking (HbTW) in the aftermath of a natural disaster. New Technol Work Employ. 2015 Mar;30(1):4761.

[64] Haynes BP, The impact of office layout on productivity. J Facil Manag., 2008.

[65] Toniolo-Barrios M, Pitt L. Mindfulness and the challenges of working from home in times of crisis., Bus. Horizons., 2020.

[66] Geng Y, Ji W, Lin B, Zhu Y. The impact of thermal environment on occupant IEQ perception and productivity. Build Environ. 2017 Aug 15;121:158-67.

[67] Tham KW. Indoor air quality and its effects on humans-A review of challenges and developments in the last 30 years. Energy Build. 2016 Oct 15;130:637-50.

[68] Jamrozik A, et al. Access to daylight and view in an office improves cognitive performance and satisfaction and reduces eyestrain: A controlled crossover study., Build. Environ., 2019.

[69] Jahncke H, Hygge S, Halin N, Green AM, Dimberg K. Open-plan office noise: Cognitive performance and restoration. J Environ Psychol. 2011 Dec 1;31(4):373-82.
[70] Robertson M, et al. The effects of an office ergonomics training and chair intervention on worker knowledge, behavior and musculoskeletal risk. Appl Ergon. 2009;40(1):124-35.

[71] Russo D, Hanel PH, Altnickel S, van Berkel N. Predictors of Well-being and Productivity among Software Professionals during the COVID-19 Pandemic-A Longitudinal Study., arXiv Prepr. arXiv2007.12580, 2020.

[72] Schieman S, Badawy PJ, Milkie M, Bierman A. WorkLife Conflict During the COVID-19 Pandemic. 2020, doi: 10.13140/RG.2.2.32315.44329.

[73] Morris J, Hassard J. Home Working? The Present and Future of How and Where We Work in the Context of COVID-19. Cardiff Business School COVID-19 and Work WP 2020, 2020. [Online]. Available: http://higherlogicdownload.s3.amazonaws.com/AOM/6f82 acc5-5f6b-41fb-a485-f1639ebcf18c/UploadedImages/ Homeworking_2_.pdf.

[74] Waizenegger L, McKenna B, Cai W, Bendz T. An affordance perspective of team collaboration and enforced working from home during COVID-19. Eur J Inf Syst. $2020 \mathrm{Jul}$ 3;29(4):429-42.

[75] Wattis L, Standing K, Yerkes MA. Mothers and work-life balance: Exploring the contradictions and complexities involved in work-family negotiation. Community Work Fam. 2013 Feb 1;16(1):1-9.

[76] Burk BN, Pechenik Mausolf A, Oakleaf L. Pandemic motherhood and the academy: A critical examination of the leisure-work dichotomy. Leis Sci. 2021 Mar 3;43(1-2):22531.

[77] Sakpere AB, Olanipekun I, Sakpere W. Work Productivity in the Period of COVID-19 Pandemic and Lockdown: A Developing World Perspective., 2020.

[78] Pew Research Center, How the Coronavirus Outbreak Has - and Hasn't - Changed the Way Americans Work, 2020. [Online]. Available: https://www.pewresearch.org/socialtrends/2020/12/09/how-the-coronavirus-outbreak-has-andhasnt-changed-the-way-americans-work/.

[79] Keeter SCOTT. People financially affected by COVID-19 outbreak are experiencing more psychological distress than others., 2020.

[80] Rodrigues MS, Leite RD, Lelis CM, Chaves TC. Differences in ergonomic and workstation factors between computer office workers with and without reported musculoskeletal pain. Work. 2017 Jan 1;57(4):563-72. 